\title{
Nanofabrication of uniform and stabilizer-free self-assembled platinum monolayers as counter electrodes for dye-sensitized solar cells
}

\author{
Lu-Lin Li, Hsin-Hui Wu, Chia-Hung Tsai and Eric Wei-Guang Diau
}

We report a two-step dip-coating approach for the fabrication of self-assembled monolayers of platinum nanocrystals (SAM-Pt) with a particle size of $\sim 3 \mathrm{~nm}$ and that are uniformly deposited on a transparent conducting oxide (TCO) surface to serve as a counter electrode (CE) for dye-sensitized solar cells (DSSCs). In the first step, we prepared a polyol solution containing $\mathrm{H}_{2} \mathrm{PtCl}_{6}$ and ethylene glycol at $110^{\circ} \mathrm{C}$, in which the reduction kinetics were controlled by adding various proportions of $\mathrm{NaOH}$. In the second step, we immersed a thiol-modified TCO substrate into the polyol solution with monodispersed Pt nanoparticles prepared at pH 3.7 at approximately $295 \mathrm{~K}$ to complete the nanofabrication. The DSSC devices using Z907 dye as a photosensitizer and the CE prepared using this SAM-Pt approach attained notable photovoltaic performance $(\eta=9.2 \%)$ comparable with those fabricated using a conventional thermal decomposition method ( $\eta=9.1 \%$ ) or a cyclic electrodeposition method $(\eta=9.3 \%)$ under the same experimental conditions. We emphasize that the SAM-Pt films feature a clean surface, uniform morphology, narrow size distribution, small Pt loading and great catalytic activity; the present approach is hence not only suitable for DSSCs but also applicable for many other energy-related applications that require platinum as an efficient catalyst.

NPG Asia Materials (2014) 6, e118; doi:10.1038/am.2014.57; published online 8 August 2014

\section{INTRODUCTION}

Dye-sensitized solar cells (DSSCs) are promising energy conversion devices for generating clean renewable energy and for decreasing the emissions of greenhouse gases with the advantages of low cost, simple processing and efficient performance. ${ }^{1,2}$ Power conversion efficiencies $(\eta)$ for converting light to electricity of greater than $11 \%$ have been obtained using ruthenium complexes ${ }^{3-6}$ and zinc porphyrins ${ }^{7,8}$ sensitized on nanoporous $\mathrm{TiO}_{2}$ films as photoanodes, using $\mathrm{I}^{-} / \mathrm{I}_{3}{ }^{-}$ or $\mathrm{Co}^{2+} / \mathrm{Co}^{3+}$ redox couples as electrolytes, and using platinized conducting glass as counter electrodes (CEs). Figure 1 shows the major components of a DSSC and the reactions of the iodine-based electrolyte related to the two electrodes. To sustain large photocurrents flowing throughout the device, $\mathrm{CE}$ materials with superior electrocatalytic ability, such as platinum $(\mathrm{Pt})$, are utilized to activate the iodine reduction reaction (IRR). This reaction converts tri-iodide anions $\left(\mathrm{I}_{3}{ }^{-}\right)$into iodide anions $\left(\mathrm{I}^{-}\right)$at the CE/electrolyte interface to provide sufficient $\mathrm{I}^{-}$species to regenerate the oxidized dye molecules, as indicated in Figure 1. The considerable cost of the Pt-based CE is, however, a major concern that limits the commercialization of DSSCs. Recent studies have focused efforts on replacing Pt with other materials as inexpensive alternatives for CEs. ${ }^{9-18}$ Although some inorganic compounds possess catalytic activity similar to that of $\mathrm{Pt}$, a deposition of thick films and nanostructures imbedded in a threedimensional matrix are typically required to achieve that similar catalytic performance, which result in an adhesion issue and opaque behavior of the CE. ${ }^{13,14} \mathrm{Pt}$ continues to be considered the most adequate material for CEs, and the most promising devices with record power conversion efficiencies contain platinized CEs. ${ }^{6-8}$

The design of catalysts for the CEs of DSSCs should be guided by the following five important characteristics: (i) excellent catalytic activity and large surface area to enhance the electrocatalytic performance; (ii) great electrical conductivity to decrease the series resistance; (iii) a low cost that is beneficial for mass production; (iv) low-temperature processing suitable for flexible devices; and (v) excellent mechanical rigidity (adhesive strength) to improve the stability endurance, especially for flexible devices. To fulfill these requirements, several strategies have been applied. For example, thermal decomposition (TD) and sputtering deposition are two standard methods for preparing a thin layer of Pt on a transparent conducting oxide (TCO) substrate as a CE. TD requires subsequent annealing at a high temperature, which makes it infeasible for flexible devices; sputtering deposition requires processing under an ultrahigh vacuum condition, in which a considerable amount of $\mathrm{Pt}$ is wasted in the chamber, which makes it unfavorable for mass production.

In contrast, electrochemical techniques, such as electrodeposition and electrophoretic deposition, are capable of preparing Pt layers at approximately $295 \mathrm{~K}$. Using this approach, we have demonstrated a uniform $\mathrm{Pt}$ nanograss structure fabricated using cyclic 


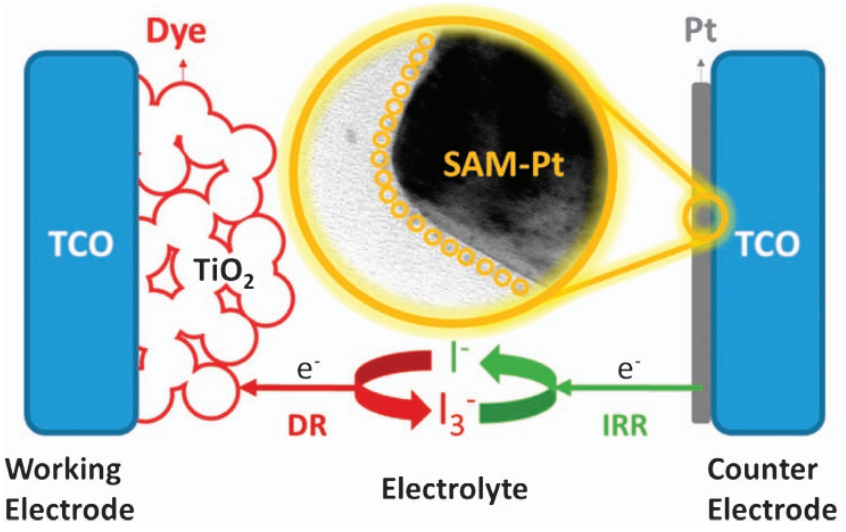

Figure 1 Schematic illustration of a DSSC device showing the three major components-dye-sensitized $\mathrm{TiO}_{2}$ working electrode, iodide-tri-iodide electrolyte and platinized counter electrode. The redox reactions involved in the interfaces between the electrolyte and the two electrodes are dye regeneration (DR; left red traces) and the IRR (right green traces). The central yellow circle highlights the surface structure for the counter electrode that consists of a self-assembled platinum monolayer (SAM-Pt) film.

electrodeposition (CED) with great electrocatalytic performance and light-scattering behavior to enhance the device performance. ${ }^{19}$ The amount of $\mathrm{Pt}$ loading is, however, a problem for the practical utilization of this method for commercialization.

Alternative chemical reductions have been developed as simple wetchemistry approaches to produce Pt nanostructures deposited on either rigid conductive glass substrates or on flexible conductive plastic substrates. ${ }^{20,21}$ With $\mathrm{NaBH}_{4}$ as a reducing agent, organic capping agents, such as polymers, surfactants or alkylthiols, were added during the reduction to inhibit the aggregation of $\mathrm{Pt}$ nanoparticles (NPs). For example, Wei et al. ${ }^{22}$ and Wang et al..$^{21}$ used poly(N-vinyl-2-pyrrolidone) and p-octyl poly-ethandiol phenyl ether (Triton), respectively, as capping agents to generate $\mathrm{Pt}$ nanoclusters as CE materials for DSSCs; Calogero et al. ${ }^{20}$ employed tetraoctyl ammonium bromide and $n$-dodecylmercaptan as capping agents to synthesize Pt NPs with a size of $\sim 5 \mathrm{~nm}$ as CE materials for DSSCs. In these methods, annealing at a high temperature (typically greater than $300^{\circ} \mathrm{C}$ ) was required to remove the organic protecting species to overcome the problems of the originally poor electron transfer and adhesion properties at the interface between Pt and TCO. Under such a thermal treatment, the shapes and the sizes of the nanostructures are difficult to control because of their deformation or aggregation at high temperatures. Although Cho et al. ${ }^{23,24}$ reported a polyol reduction to prepare Pt CEs for DSSCs at temperatures of 160$180^{\circ} \mathrm{C}$, it is difficult to prepare the thin layer of Pt nanostructures with a uniform morphology and size distribution on TCO at temperatures near $295 \mathrm{~K}$, in particular, to obtain the advantages of excellent electrocatalytic function, large active surface area and effective adhesion to the substrate. As highlighted in Figure 1, in the present work, we demonstrate a feasible strategy for preparing self-assembled Pt monolayers (SAM-Pt) on the surface of TCO in two steps without adding a surfactant or protective agent; thus, the postheating step is avoided.

\section{MATERIALS AND METHODS}

\section{Fabrication of Pt CEs}

SAM-Pt CE. (i) Stabilizer-free Pt NPs were synthesized via the reduction of $\mathrm{H}_{2} \mathrm{PtCl}_{6}$ in EG according to the polyol method under various $\mathrm{pH}$ conditions. The polyol solutions were prepared by mixing $\mathrm{H}_{2} \mathrm{PtCl}_{6} / \mathrm{EG}(3.0 \mathrm{ml}, 5 \mathrm{~mm})$ and various amounts $(x \mathrm{ml})$ of $\mathrm{NaOH} / \mathrm{EG}$ solutions. Then, $(27-x \mathrm{ml}, 0.06 \mathrm{M})$ of EG was added to the mixture to maintain $(30 \mathrm{ml})$ the total volume of the polyol solution constant. As $x$ was varied from $0,1.2,1.8$ to 3.7 , the $\mathrm{pH}$ values were adjusted to 1.5 (without $\mathrm{NaOH}$ ), 2.0, 3.7 and 5.6, respectively. The mixture was thoroughly stirred and refluxed on heating to $110^{\circ} \mathrm{C}$ within $30 \mathrm{~min}$, and the reaction was held at $110^{\circ} \mathrm{C}$ for $4 \mathrm{~h}$. (ii) The modification of the substrates was achieved through two consecutive steps. First, 'piranha' treatment was performed by immersing the TCO substrates into a 'piranha' solution that contained concentrated $\mathrm{H}_{2} \mathrm{SO}_{4} / \mathrm{H}_{2} \mathrm{O}_{2}$ with a volume ratio of 4/1 for $3 \mathrm{~min}$ to clean the surface and to activate the surface hydroxylation. After washing with deionised water, the substrates were subsequently immersed into a solution containing MPTMS, $0.56 \mathrm{M}$ at $295 \mathrm{~K}$ for $1 \mathrm{~h}$ and then thoroughly rinsed with ethanol to remove the unbound silane molecules. The functionalized TCO substrates were immersed into a stock polyol solution prepared in (i) for $12 \mathrm{~h}$. The as-prepared SAM-Pt films were rinsed with ethanol to remove all unwanted residues and dried with $\mathrm{N}_{2}$.

CED-Pt CE. Cyclic electrodeposition was used to fabricate CED-Pt CE at $295 \mathrm{~K}$ with an electrochemical system (CHI 621, CH Instruments, Austin, TX, USA) and a three-electrode system. ${ }^{19}$ The TCO substrates were immersed into an aqueous solution containing $\mathrm{NaNO}_{3}(5 \mathrm{~mm})$ and $\mathrm{H}_{2} \mathrm{PtCl}_{6}(5 \mathrm{~mm})$ with a potential scan controlled over the range of $-1.0-0.2 \mathrm{~V}$ at a scan rate of $0.05 \mathrm{~V} \mathrm{~s}^{-1}$ for 10 cycles.

TD-Pt CE. To prepare a conventional thermal reduction platinized CE, a Ptcontaining solution $\left(\mathrm{H}_{2} \mathrm{PtCl}_{6}\right.$ in isopropanol) was spin-coated onto TCO glass at 2000 r.p.m. for $10 \mathrm{~s}$; the resulting film was heated at $380^{\circ} \mathrm{C}$ for $30 \mathrm{~min}$. The TD process was repeated twice to complete the fabrication. The morphologies of the Pt NP monolayer and elemental mapping of Pt were observed with a field-emission scanning electron microscope (JSM-6390LV, JEOL Ltd., Tokyo, Japan) equipped with an energy dispersive X-ray spectrometer. TEM images were recorded (JEM-2100F, JEOL Ltd.); the TEM specimens were prepared by mechanical polishing and ion milling (Precision ion polishing system, Model 691, Gatan, CA, USA) of the cross section of the interface between the SAM-Pt and the FTO substrate. The Pt-loading amount on the supporting materials of the Pt CE was determined through analyses with an inductively coupled plasma mass spectrometer (ELAN 6100 DRC, PerkinElmer Sciex, Boston, MA, USA) via dissolving the Pt $\mathrm{CE}\left(1 \times 1 \mathrm{~cm}^{2}\right)$ in an $\mathrm{HF}$ solution for 1 day.

\section{Electrochemical measurements}

Electrocatalytic measurements of the tri-iodide reduction were performed in $\mathrm{CH}_{3} \mathrm{CN}$ solution ( $\mathrm{LiI} 0.01 \mathrm{M}, \mathrm{I}_{2} 0.001 \mathrm{M}, \mathrm{LiClO}_{4} 0.1 \mathrm{M}$ ) at a scan rate of $100 \mathrm{mV} \mathrm{s}^{-1}$ using cyclic voltammograms analysis. EIS of the corresponding DSSC devices were measured with an electrochemical system (Model IM 6, Zahner, Kansas City, MO, USA) at the open-circuit voltage under one-sun AM-1.5 irradiation. The frequency range was $0.03-1 \mathrm{MHz}$; the magnitude of the alternating potential was $10 \mathrm{mV}$. The EIS data were analyzed with an appropriate equivalent circuit using Z-view simulation software (Z-view, Scribner Associates Inc., Southern Pines, NC, USA).

\section{Device fabrication and characterization}

$\mathrm{TiO}_{2}$ NPs were prepared using a normal sol-gel/hydrothermal method. A paste composed of $\mathrm{TiO}_{2} \mathrm{NPs}$ (particle size $\sim 20 \mathrm{~nm}$ ) was coated via screen printing onto a $\mathrm{TiCl}_{4}$-pretreated FTO glass $(8 \Omega / \square)$. A scattering layer (ST41, Ishihara Sangyo Kaisha, Osaka, Japan, particle size $\sim 300 \mathrm{~nm}$ ) was also screen printed onto the active layer to improve the performance of the solar cell. The thickness of the transparent active layer was $\sim 14 \mu \mathrm{m}$ and that of the scattering layer was $\sim 5 \mu \mathrm{m}$. The as-prepared $\mathrm{TiO}_{2}$ films (active size of $0.4 \times 0.4 \mathrm{~cm}^{2}$ ) were sensitized in a solution (Z907 dye, Everlight Chemical Industrial Corp., Taipei, Taiwan, $\left.3 \times 10^{-4} \mathrm{M}\right)$ containing chenodeoxycholic acid $\left(3 \times 10^{-4} \mathrm{M}\right)$ in acetonitrile/t-butanol $(v / v=1: 1)$ binary solvent for $8 \mathrm{~h}$. After washing with ethanol, the sensitized working electrode was assembled with a Pt CE-SAMPt, CED-Pt or TD-Pt—and sealed with a hot-melt film (SX1170, Solaronix, Switzerland, thickness of $25 \mu \mathrm{m})$. The electrolyte solution contained 1-methyl3-propylimidazolium iodide $(1.0 \mathrm{M})$, guanidinium thiocyanate $(0.1 \mathrm{M})$, LiI $(0.05 \mathrm{M}), \mathrm{I}_{2}(0.03 \mathrm{M})$ and 4-t-butylpyridine $(0.5 \mathrm{M})$ in a solvent mixture 
containing acetonitrile and valeronitrile (volume ratio of $85: 15$ ). The currentvoltage characteristics of the devices were measured with a digital source meter (Model 2400, Keithley Instruments, Inc., Cleveland, OH, USA, computercontrolled) under one-sun AM-1.5 G irradiation from a solar simulator (XES502S, SAN-EI ELECTRIC Co., Ltd., Osaka, Japan). The spectra of the conversion efficiency of incident photons to current of the corresponding devices were recorded with a system consisting of a Xe lamp (A-1010, Photon Technology International, Edison, NJ, USA, 150 W), a monochromator (PTi, $1200 \mathrm{~g} \mathrm{~mm}^{-1}$ blazed at $500 \mathrm{~nm}$ ), and a source meter (Keithley 2400).

\section{RESULTS AND DISCUSSION}

Surface modifications for self-assembled Pt monolayers on TCO

The concept of preparing a thin Pt film with a SAM nature involves modifying the surface of TCO with specific functional groups that strongly interact with the uniform Pt NPs prepared previously in a polyol solution. Scheme 1 summarizes all major steps for preparing a SAM-Pt film on a TCO substrate through two modifications of the surface. First, the TCO substrate was cleaned in a hot 'piranha' solution to generate active hydroxyl groups $(-\mathrm{OH})$ on the surface. The bottom left panels of Scheme 1 show that the water-contact angles on the TCO substrate decrease from $24.5^{\circ}$ to $20.3^{\circ}$ because of the increased hydrophilicity of the surface after the hydroxylation. Second, the hydrophilic TCO substrate was treated with a bifunctional organosilane compound in which one side contains a functional group such as $-\mathrm{NH}_{2},-\mathrm{SH}$ or $-\mathrm{COOH}$ to interact with the Pt NPs and the other side contains a Si-O-Si bond to form a densely packed silane SAM on the surface of TCO. In our approach, the $\mathrm{OH}$-modified TCO substrate was dipped into a solution containing 3-mercaptopropyl(trimethoxysilane) (MPTMS, $0.56 \mathrm{M}$ ) in ethanol at $295 \mathrm{~K}$ to create a thiol-functionalized silane SAM film on TCO. After this treatment, the contact angle of water on the TCO surface increased to $70.0^{\circ}$, which is consistent with that reported in the literature $\left(69^{\circ}\right),{ }^{25}$ thereby confirming the formation of a dense MPTMS monolayer on TCO.

Preparation of monodispersed Pt NP solutions controlled by $\mathrm{pH}$ The solution containing monodispersed Pt NPs was prepared through polyol chemical reduction. ${ }^{26-28}$ Ethylene glycol (EG) was used in the polyol approach to serve not only as a solvent to dissolve the $\mathrm{H}_{2} \mathrm{PtCl}_{6}$ precursor but also as a gentle reducing agent to produce the required Pt NPs with a uniform size. Xia et al. ${ }^{26,27}$ demonstrated that a shape- controlled synthesis of Pt nanocrystals is achievable during the polyol reduction of a Pt precursor in the presence of a capping agent and a $\mathrm{Fe}^{\mathrm{III}}$ species in a trace amount under oxygen-free conditions. To generate a clean surface for the deposition of the SAM-Pt film on TCO for our purpose, the presence of any organic capping agents or ionic species in the polyol solution should be avoided. Rather than adding a capping agent to protect the reduced Pt NPs from further aggregation, we added various proportions of $\mathrm{NaOH}$ to the polyol solutions to control the rate of reduction to form Pt NPs under various $\mathrm{pH}$ conditions. ${ }^{23,28,29}$ The $\mathrm{SH}$-modified TCO substrate was then immersed in the Pt NP solution prepared at $295 \mathrm{~K}$ for $12 \mathrm{~h}$ to complete the formation of SAM-Pt on a clean surface of TCO. The bottom right panel of Scheme 1 shows an energy dispersive X-ray spectrometer mapping image of a SAM-Pt on a fluorine-doped tin oxide (FTO) glass substrate (also shown in Supplementary Figure S1), demonstrating the uniform morphology of the SAM-Pt NP synthesized under conditions free of stabilizer and with a controlled $\mathrm{pH}$.

The key to producing a clean surfactant-free SAM-Pt surface with enhanced IRR activity is to control the size of the Pt NPs with sufficient uniformity in the polyol solution. In our approach, the $\mathrm{pH}$ of the solution was adjusted in the range of 1.5-5.6 to control the formation of Pt NPs and to avoid the aggregation of Pt NPs in the solution. The effect of $\mathrm{pH}$ on the formation of Pt NPs was easily observed from the suspensions in the solutions (inset of Figure 2) and confirmed with the absorption spectra shown in Figure 2. The spectrum of the starting material, the yellowish $\mathrm{H}_{2} \mathrm{PtCl}_{6} / \mathrm{EG}$ solution, shows a maximum absorption at $268 \mathrm{~nm}$ attributed to the transition involving ligand-to-metal charge transfer (LMCT) of the $\mathrm{H}_{2} \mathrm{PtCl}_{6}$ precursor. $^{30}$ As the reduction of $\mathrm{Pt}^{\mathrm{IV}}$ to $\mathrm{Pt}^{0}$ by $\mathrm{EG}$ proceeded, the absorption at $268 \mathrm{~nm}$ decreased, and it eventually disappeared when the reduction was complete. Particles with a large size induce Mei scattering that is indicated by large offsets in the absorption spectra. Consequently, the offset absorbance was large at $\mathrm{pH} 1.5$ (no $\mathrm{NaOH}$ added) and decreased with increasing $\mathrm{pH}$ until $\mathrm{pH} 3.7$, indicating that the size of polyol-reduced Pt NPs had a tendency to depend on $\mathrm{pH} 1.5>2.0>3.7$. At $\mathrm{pH} 5.6$, the reduction was too slow to be completed within a typical reaction period $(4 \mathrm{~h})$; the corresponding spectrum retained the LMCT characteristic of the precursor. The kinetics of the reduction must play an important role in controlling the crystal growth to form Pt NPs with various sizes, as observed in this study.

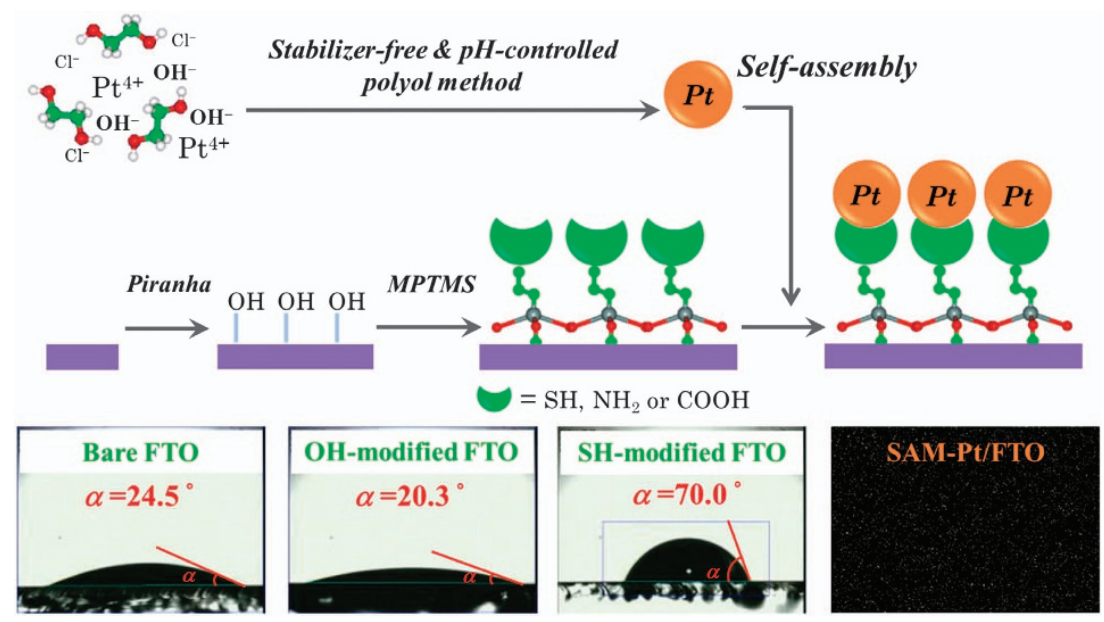

Scheme 1 Schematic representation of the fabrication of platinum nanoparticles self-assembled on the surface of an FTO substrate using a two-step dipcoating procedure. 
Effect of aggregation of Pt NPs on TCO under various $\mathrm{pH}$ conditions

We fabricated Pt CEs using the four polyol solutions shown in Figure 2 by dip coating at a temperature near $295 \mathrm{~K}$, as demonstrated in Scheme 1. Figures 3a-d show the surface morphologies of the TCO substrates decorated with Pt NP solutions prepared at $\mathrm{pH}$ 1.5, 2.0, 3.7 and 5.6, respectively. In the $\mathrm{pH}$ condition without added base, the $\mathrm{Pt}^{\mathrm{IV}}$ species were rapidly reduced to $\mathrm{Pt}^{0}$ (mechanism to be discussed), and a uniform growth of crystals was difficult to generate under this condition. Consequently, irregular nanoclusters formed through the agglomeration of Pt NPs with uneven coverage on the surface of the

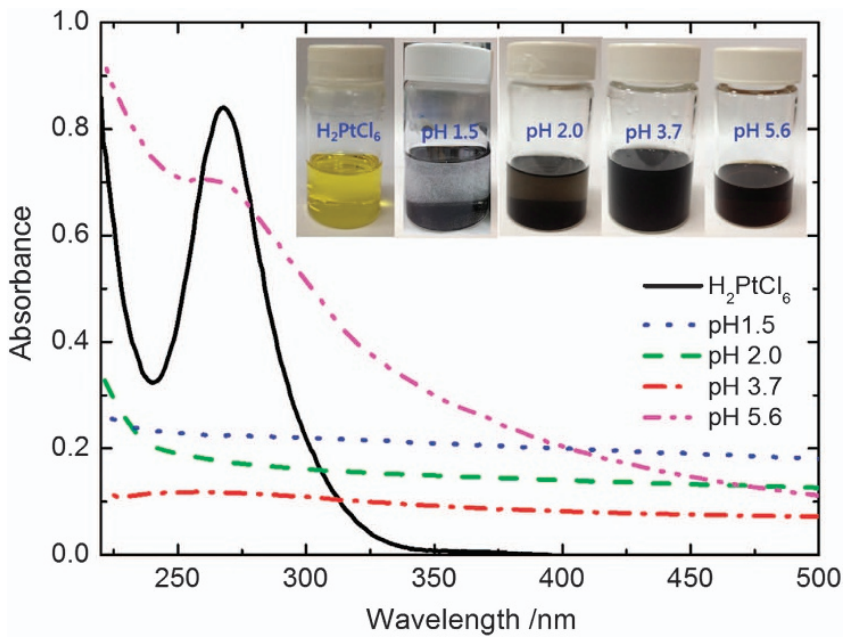

Figure 2 UV/Visible absorption spectra of the polyol solutions under various $\mathrm{pH}$ conditions, as indicated. The photographs in the inset show the visua appearances of the corresponding stock polyol solutions.

a

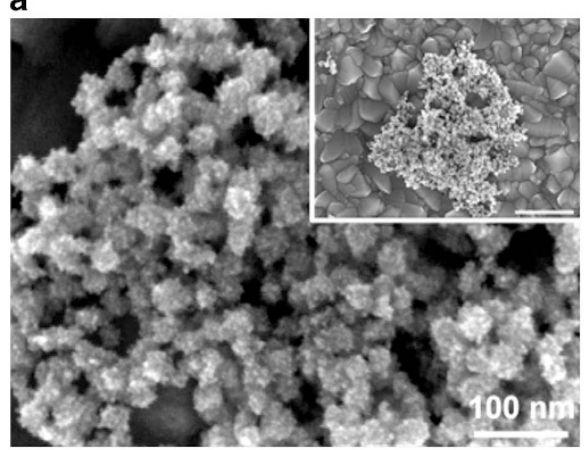

C

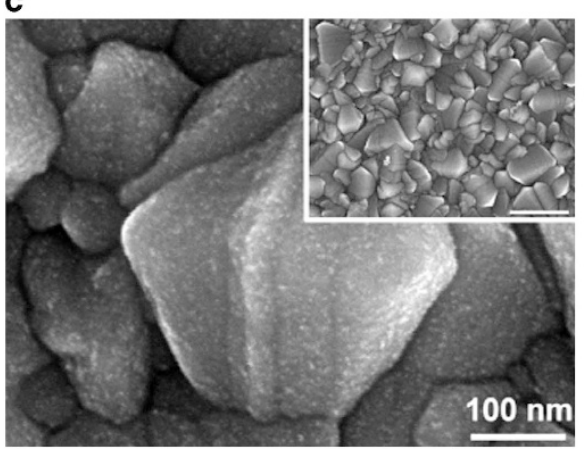

TCO substrate (Figure 3a). At $\mathrm{pH} 2.0$, the Pt nanoclusters became smaller and aggregated to form a branch-like structure; the size distribution and the surface coverage were, however, still poor (Figure 3b). When the $\mathrm{pH}$ was increased to 3.7, a uniform morphology of Pt NPs with a particle size of less than $10 \mathrm{~nm}$ was observed (Figure 3c), which is consistent with the energy dispersive $\mathrm{X}$-ray spectrometer-mapping image of elemental Pt (Supplementary Figure S1) showing a well-dispersed coverage of SAM-Pt (to be demonstrated with the transmission electron microscopy (TEM) images) on the TCO surface. As the $\mathrm{pH}$ was increased to 5.6, the formation of Pt NPs on TCO was scarcely observable in the scanning electron microscope images (Figure 3d), which is consistent with the absorption spectrum shown in Figure 2, because the reduction was slow with a high concentration of $\mathrm{NaOH}$.

\section{Mechanism of polyol reduction under various $\mathrm{pH}$ conditions}

Why did the reduction in the polyol reaction becomes slower in the presence of $\mathrm{NaOH}$ ? To answer this question, we performed controlled experiments for the reaction to attain the optimal conditions (temperature of $110^{\circ} \mathrm{C}$ and time of $4 \mathrm{~h}$ ) at $\mathrm{pH} 3.7$; the results are presented in Supplementary Figure S2. The intensity of the characteristic LMCT feature at $268 \mathrm{~nm}$ decreased during the first $10 \mathrm{~min}$ when the temperature increased to $53^{\circ} \mathrm{C}$, but it slightly increased as the reaction temperature reached $70^{\circ} \mathrm{C}$; afterwards, the intensity of the LMCT signal rapidly decreased as the reduction proceeded. Under the condition of $70{ }^{\circ} \mathrm{C}$ without the addition of $\mathrm{NaOH}(\mathrm{pH} 1.5)$, we observed that the original LMCT feature significantly decreased and was accompanied with a new band at $249 \mathrm{~nm}$ (Supplementary Figure S3). This signal is clear evidence for the formation of a $\mathrm{Pt}^{\mathrm{II}}$ intermediate, presumably the solvated $\mathrm{PtCl}_{4}{ }^{2-}$ species, during polyol reduction at $\mathrm{pH} 1.5$, similar to many examples reported by Xia et al. ${ }^{26,27,30}$ In contrast, the formation of the $\mathrm{Pt}^{\mathrm{II}}$ intermediate with an

\section{b}

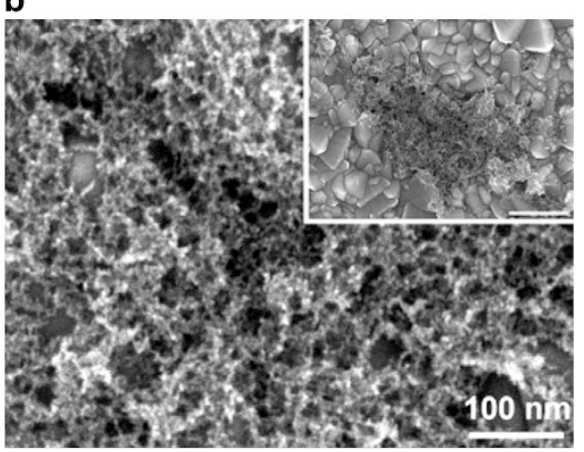

d

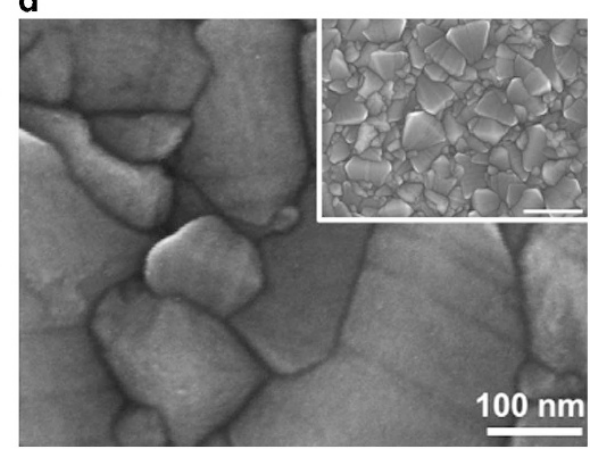

Figure 3 Scanning electron microscope images of the SAM-Pt counter electrodes fabricated under various pH conditions: (a) 1.5 (b) 2.0 (c) 3.7 and (d) 5.6. The insets show the corresponding images in large areas, with the scale bars representing $500 \mathrm{~nm}$. 
absorption band at $\sim 250 \mathrm{~nm}$ was not evident in the case of $\mathrm{pH} 3.7$; instead, we observed the recovery of the absorbance at $268 \mathrm{~nm}$ with a broad spectral feature. This observation might indicate that the reaction reverted to the $\mathrm{Pt}^{\mathrm{IV}}$ species, as proposed by Herricks et al. ${ }^{30}$ We therefore hypothesize that the formation of hydroxo-chloro $\mathrm{Pt}^{\mathrm{IV}}$ complexes, $\mathrm{Pt}(\mathrm{OH})_{n} \mathrm{Cl}_{6-n}{ }^{2-}$, might be involved during the initial stage of the polyol reduction in the presence of $\mathrm{NaOH}$. This mechanism is consistent with that proposed by Ren and Xing, ${ }^{28}$ who indicated the formation of hydroxo-chloro $\mathrm{Pt}{ }^{\mathrm{II}}$ complexes, $\mathrm{Pt}(\mathrm{OH})_{n} \mathrm{Cl}_{4-n}{ }^{2-}$, during the hydrolysis of a $\mathrm{Pt}^{\mathrm{II}}$ precursor at a high $\mathrm{pH}$. In our case, the hydrolysis to form $\mathrm{Pt}(\mathrm{OH})_{n} \mathrm{Cl}_{6-n}{ }^{2}$ - competed with the reduction of $\mathrm{Pt}^{\mathrm{IV}}$ to $\mathrm{Pt}^{0}$ via a $\mathrm{Pt}^{\mathrm{II}}$ intermediate $\mathrm{PtCl}_{4}{ }^{2-}$; further reduction of the $\mathrm{Pt}(\mathrm{OH})_{n} \mathrm{Cl}_{6-n}{ }^{2-}$ complexes would become a rate-determining step to significantly slow the reduction at higher $\mathrm{pH}$.

\section{Formation of true SAM-Pt on TCO}

To confirm the formation of a real self-assembled monolayer of $\mathrm{Pt}$ NPs on the TCO surface, we examined the surface morphology of the SAM-Pt/FTO substrate using a high-resolution TEM (HRTEM). Figures $4 \mathrm{a}-\mathrm{d}$ show HRTEM images at four magnifications for the SAM-Pt/FTO CE fabricated according to the above approach ( $\mathrm{pH}$ 3.7). A thin layer of a SAM-Pt film with a uniform size distribution produced on the surface of FTO was unambiguously observed according to these HRTEM images; this observation consolidates our concept to design the SAM-Pt material as a CE for DSSCs. Based on the morphology of the SAM-Pt film, as clearly

a

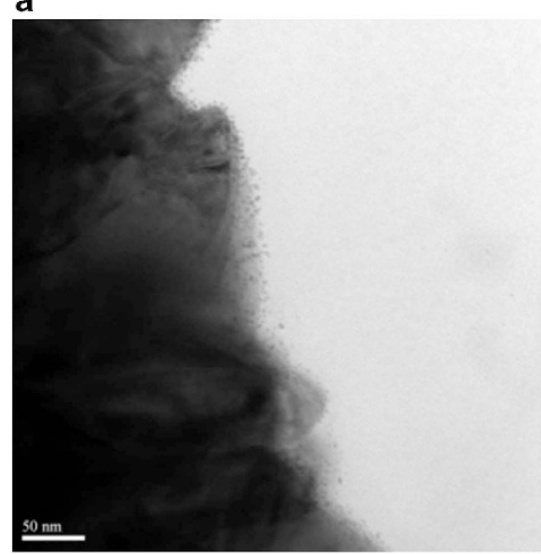

c

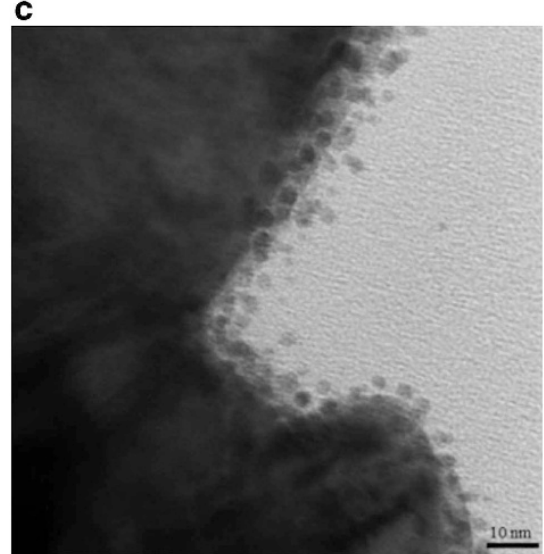

shown in Figure 4c, we estimated the size distribution of the $\mathrm{Pt}$ NPs based on a statistical analysis of the individual NPs, which yielded a mean particle size of $3 \mathrm{~nm}$ with a narrow distribution (Supplementary Figure S4). The homogeneous Pt NPs uniformly covered the surface of the substrate, and they were insensitive to the topography of the substrate, even on the rough surfaces of FTO and indium tin oxide (ITO). We expect that an excellent binding interaction was created between the uniform Pt NPs and the surface modified with silane SAM, as clearly demonstrated in Scheme 1. Moreover, the size of the Pt NPs was controlled to a very small scale, $\sim 3 \mathrm{~nm}$, which is beneficial for maximizing the surface area to obtain great catalytic performance with less Pt loading, as required for commercialization.

The inset of Figure $4 \mathrm{~d}$ shows the fine lattice structure of the $\mathrm{Pt}$ NPs, indicating that the distance between the adjacent lattice fringes is $0.23 \mathrm{~nm}$, which is consistent with the interplanar spacing of the facet $\{111\}$ in the Pt lattice. Hou et al. ${ }^{16}$ reported that $\mathrm{Pt}(111)$ plays an important role in affecting the catalytic function of IRR through the binding ability of the tri-iodide species on the surface of $\mathrm{Pt}(111)$. Pt nanocrystals with greater portions of exposed facets $\{111\}$ therefore exhibit enhanced activity and stability for the IRR. The clean surfaces of the Pt NPs prepared using our SAM approach have an advantage to prevent the hindrance of the capping agents between $\mathrm{Pt}$ atoms and tri-iodide anions to effectively enhance the activity of the IRR when the SAM-Pt material is used as a CE for DSSCs.

b

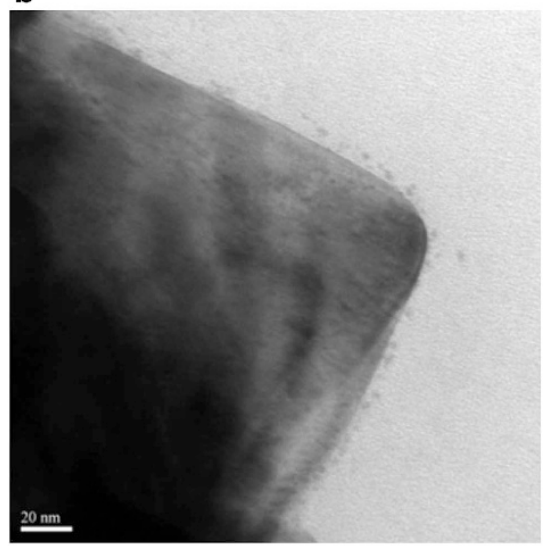

d

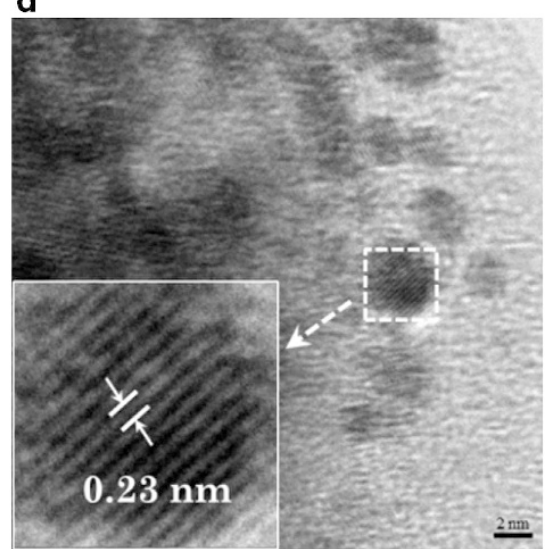

Figure 4 TEM images of the SAM-Pt counter electrodes fabricated under the $\mathrm{pH} 3.7$ condition showing a uniform spherical morphology of Pt nanocrystals self-assembled on the rough surface of TCO. The scale bars represent (a) $50 \mathrm{~nm}$, (b) $20 \mathrm{~nm}$, (c) $10 \mathrm{~nm}$ and (d) $2 \mathrm{~nm}$. The inset of $\mathbf{d}$ shows the fine structure of the Pt lattice with a distance of $0.23 \mathrm{~nm}$ between the $\{111\}$ facets. 
Photovoltaic performance and electrocatalytic activity of SAM-Pt CE for DSSCs

To investigate the DSSC device performance, we prepared two types of SAM-Pt CEs: one on thermally stable FTO $(8 \Omega / \square)$ and the other on thermally unstable ITO $(2.8 \Omega / \square)$ substrates. For comparison, we fabricated a Pt CE using TD to deposit Pt on FTO and CED to deposit Pt on ITO under the same experimental conditions. ${ }^{19}$ Figures $5 \mathrm{a}$ and $\mathrm{b}$ show the current-voltage characteristics and the corresponding incident photon-to-current conversion efficiency action spectra, respectively, with the devices composed of a stable Z907 dye (shown in Figure 5b). ${ }^{31}$ Figure $5 c$ shows the cyclic voltammograms of the $\mathrm{I}^{-} / \mathrm{I}_{3}{ }^{-}$redox couple for the corresponding CEs; Figure $5 \mathrm{~d}$ shows the electrochemical impedance spectra (EIS) for the corresponding devices with the theoretical fits according to an appropriate equivalent circuit model. ${ }^{32}$ The corresponding photovoltaic and EIS parameters are summarized in Table 1.

In general, the power conversion efficiencies of these devices are similar, but the ITO-based devices perform slightly better than the FTO-based devices because of the smaller series resistance $\left(R_{\mathrm{s}}\right.$; Table 1) of the former than the latter. The ITO substrate is, however, thermally unstable; therefore, the traditional TD treatment becomes impractical. The best device was composed of the CED-Pt/ITO substrate because of its superior cyclic voltammograms characteristics (Figure 5c) and small impedance for charge transfer at the CE/electrolyte interface $\left(R_{\mathrm{ct}}\right.$; Table 1$)$. A large Pt loading is required for the CE generated using the CED method: the amount of $\mathrm{Pt}$ loading was determined with an inductively coupled plasma mass spectrometer, for which the ratios of Pt loading were determined to be 1.0, 1.2 and 25.8 for the CEs composed of SAM-Pt, TD-Pt and CED-Pt, respectively. The Pt loading on the TCO substrate is an important factor to consider for the future commercialization of DSSCs. The excellent device performance with a minimum Pt loading suggests that the monolayer-deposited SAM-Pt materials have considerable promise as potential CEs for commercialization.

\section{CONCLUSION}

In the present work, we have developed a nanofabrication strategy to prepare monolayers of Pt NPs self-assembled on a rough TCO surface in two steps: first, preparing a well-dispersed Pt NP solution from polyol reduction at $110^{\circ} \mathrm{C}$ at a $\mathrm{pH}$ that is well controlled by adding $\mathrm{NaOH}$; second, dipping the SAM-functionalized TCO substrate, prepared beforehand using 'piranha' and MPTMS surface treatments in turn, into the Pt NP solution at a temperature near $295 \mathrm{~K}$ to complete the fabrication of the SAM-Pt CE for DSSCs. The $\mathrm{pH}$ plays a key role in the reduction kinetics to control the size of the Pt NPs formed in the polyol solution. The best condition was found to be $\mathrm{pH}$ 3.7, at which the aggregation of Pt NPs on the TCO surface is entirely avoided, as evidenced with the scanning electron microscope and energy dispersive X-ray spectrometer mapping images. A true selfassembled Pt nanocrystalline monolayer with a mean particle size of $3 \mathrm{~nm}$ exposed at facet $\{111\}$ uniformly deposited on the surface of TCO was unambiguously observed via the HRTEM images. The uniform SAM-Pt film with a narrow size distribution can be produced on TCO without a stabilizer; thus, the traditional thermal treatment at high temperatures is no longer required. The uniform nature of the SAM-Pt film has the advantages of minimizing the amounts of Pt loading and optimizing the catalytic function on the TCO surface. The DSSC devices prepared according to this SAM-Pt approach attained notable photovoltaic performance $(\eta=9.2 \%)$ comparable with those fabricated with a conventional TD method $(\eta=9.1 \%)$ or a CED method $(\eta=9.3 \%)$ under the same experimental conditions. We emphasize that the SAM-Pt films feature a clean surface (no thermal treatment is necessary), uniform morphology, narrow size distribution, small Pt loading and great catalytic

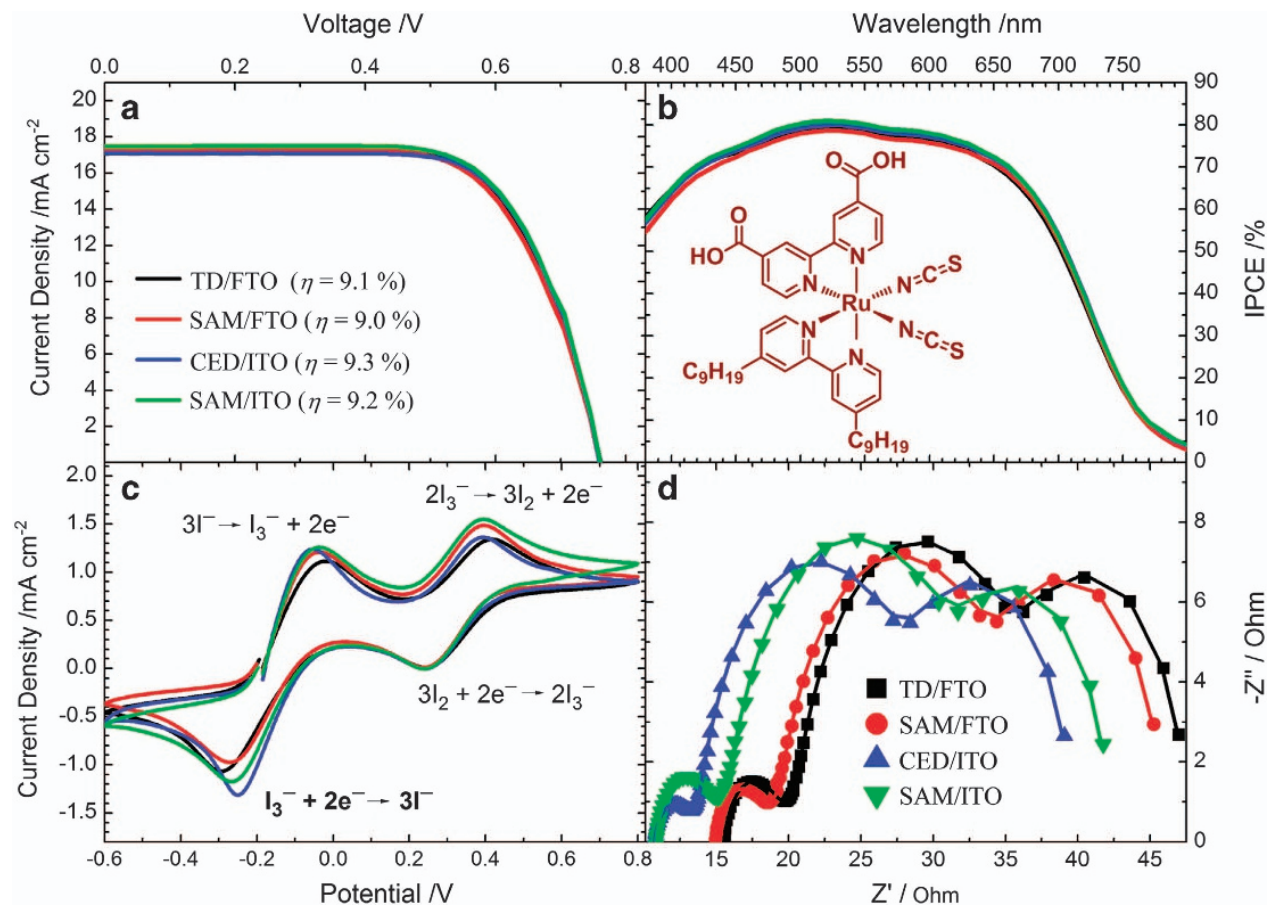

Figure 5 Photovoltaic and electrochemical characteristics of the devices fabricated using various types of platinized counter electrodes, as indicated: (a) current-voltage curves; (b) incident photon-to-current conversion efficiency (IPCE) action spectra; (c) cyclic voltammograms (CV) showing two pairs of redox reactions for the Pt CE in iodide-tri-iodide electrolyte; and (d) EIS of the corresponding devices. The inset of $\mathbf{b}$ shows the molecular structure of the Z907 dye. 
Table 1 Photovoltaic and EIS parameters of DSSC devices fabricated with $\mathrm{Z907}$ dye and various platinized counter electrodes (Pt CEs) under AM $1.5 \mathrm{G}$ one-sun irradiation with an active area $0.16 \mathrm{~cm}^{2}$

\begin{tabular}{lcccccc}
\hline Counter electrode $^{\mathrm{a}}$ & $J_{S O} / \mathrm{mAcm}^{-2}$ & $V_{\text {Od }} \mathrm{mV}$ & FF & $\eta / \%$ & $R_{S} / \Omega$ & $R_{c t} / \Omega$ \\
\hline TD/FTO & 17.2 & 765 & 0.691 & 9.1 & 15.2 & 4.0 \\
SAM/FTO & 17.2 & 770 & 0.682 & 9.0 & 14.7 & 3.3 \\
CED/ITO & 17.1 & 774 & 0.701 & 9.3 & 10.5 & 2.3 \\
SAM/ITO & 17.4 & 764 & 0.691 & 9.2 & 10.7 & 3.7
\end{tabular}

Abbreviations: CED, cyclic electrodeposition; DSSC, dye-sensitized solar cell; EIS, electrochemical impedance spectra; FF, fill factor; FTO, fluorine-doped tin oxide; ITO, indium tin oxide; $J_{S C}$, short circuit current density; SAM, self-assembled monolayer; $R_{S}$, resistance in series; $R_{c t}$, counter electrode/electrolyte interface; TD, thermal decomposition; $V_{O C}$, open circuit voltage.

aThe Pt CEs were fabricated using the techniques of thermal decomposition, cyclic electrodeposition and self-assembled monolayer deposited on either a fluorine-doped tin oxide or an indium tin oxide glass substrate.

activity; the present approach is hence not only suitable for DSSCs but is also promising for many other energy-related applications that require $\mathrm{Pt}$ as an efficient catalyst to expedite the oxygen reduction reaction. ${ }^{33-35}$

\section{ACKNOWLEDGEMENTS}

We thank Dr Meng-Hung Lin for his assistance in collecting the TEM images. The Ministry of Science and Technology of Taiwan and the Ministry of Education of Taiwan, under the ATU program, provided financial support for this project.

1 Oregan, B. \& Grätzel, M. A Low-cost, high-efficiency solar-cell based on dye-sensitized colloidal $\mathrm{TiO}_{2}$ films. Nature 353, 737-740 (1991).

2 Hagfeldt, A., Boschloo, G., Sun, L. C., Kloo, L. \& Pettersson, H. Dye-sensitized solar cells. Chem. Rev. 110, 6595-6663 (2010).

3 Nazeeruddin, M. K., De Angelis, F., Fantacci, S., Selloni, A., Viscardi, G., Liska, P., Ito, S., Takeru, B. \& Grätzel, M. Combined experimental and DFT-TDDFT computational study of photoelectrochemical cell ruthenium sensitizers. J. Am. Chem. Soc. 127, 16835-16847 (2005)

4 Chen, C. Y., Wang, M., Li, J. Y., Pootrakulchote, N., Alibabaei, L., Ngoc-le, C. H., Decoppet, J. D., Tsai, J. H., Grätzel, C., Wu, C. G., Zakeeruddin, S. M. \& Grätzel, M. Highly efficient light-harvesting ruthenium sensitizer for thin-film dye-sensitized solar cells. ACS Nano 3, 3103-3109 (2009).

5 Yu, Q. J., Wang, Y., Yi, Z., Zu, N., Zhang, J., Zhang, M. \& Wang, P. High-efficiency dye-sensitized solar cells: the influence of lithium ions on exciton dissociation, charge recombination, and surface states. ACS Nano 4, 6032-6038 (2010).

6 Han, L., Islam, A., Chen, H., Malapaka, C., Chiranjeevi, B., Zhang, S., Yang, S. \& Yanagida, M. High-efficiency dye-sensitized solar cell with a novel co-adsorbent. Energy Environ. Sci. 5, 6057-6060 (2012).

7 Yella, A., Lee, H. W., Tsao, H. N., Yi, C., Chandiran, A. K., Nazeeruddin, M. K., Diau, E. W., Yeh, C. Y., Zakeeruddin, S. M. \& Grätzel, M. Porphyrin-sensitized solar cells with cobalt (II/III)-based redox electrolyte exceed 12 percent efficiency. Science 334, 629-634 (2011)

8 Li, L. L. \& Diau, E. W. G. Porphyrin-sensitized solar cells. Chem. Soc. Rev. 42, 291-304 (2013).

9 Wu, M. \& Ma, T. Platinum-free catalysts as counter electrodes in dye-sensitized solar cells. ChemSusChem 5, 1343-1357 (2012)

10 Burschka, J., Brault, V., Ahmad, S., Breau, L., Nazeeruddin, M. K., Marsan, B., Zakeeruddin, S. M. \& Grätzel, M. Influence of the counter electrode on the photovoltaic performance of dye-sensitized solar cells using a disulfide/thiolate redox electrolyte. Energy Environ. Sci. 5, 6089-6097 (2012).

11 Kwon, W., Kim, J.-M. \& Rhee, S.-W. Electrocatalytic carbonaceous materials for counter electrodes in dye-sensitized solar cells. J. Mater. Chem. A 1, 3202-3215 (2013).

12 Xue, Y., Liu, J., Chen, H., Wang, R., Li, D., Qu, J. \& Dai, L. Nitrogen-doped graphene foams as metal-free counter electrodes in high-performance dye-sensitized solar cells. Angew. Chem. Int. Ed. 51, 12124-12127 (2012).

13 Wu, M., Lin, X., Wang, Y., Wang, L., Guo, W., Qi, D., Peng, X., Hagfeldt, A., Grätzel, M. \& Ma, T. Economical Pt-free catalysts for counter electrodes of dye-sensitized solar cells. J. Am. Chem. Soc. 134, 3419-3428 (2012).
14 Chi, W. S., Han, J. W., Yang, S., Roh, D. K., Lee, H. \& Kim, J. H. Employing electrostatic self-assembly of tailored nickel sulfide nanoparticles for quasi-solid-state dye-sensitized solar cells with Pt-free counter electrodes. Chem. Commun. 48, 9501-9503 (2012).

15 Xu, H., Zhang, X., Zhang, C., Liu, Z., Zhou, X., Pang, S., Chen, X., Dong, S., Zhang, Z., Zhang, L., Han, P., Wang, X. \& Cui, G. Nanostructured titanium nitride/PEDOT:PSS composite films as counter electrodes of dye-sensitized solar cells. ACS Appl. Mater. Interfaces 4, 1087-1092 (2012).

16 Hou, Y., Wang, D., Yang, X. H., Fang, W. Q., Zhang, B., Wang, H. F., Lu, G. Z., Hu, P., Zhao, H. J. \& Yang, H. G. Rational screening low-cost counter electrodes for dye-sensitized solar cells. Nat. Commun. 4, 1583 (2013).

17 Yi, L., Liu, Y., Yang, N., Tang, Z., Zhao, H., Ma, G., Su, Z. \& Wang, D. One dimensional CulnS2-ZnS heterostructured nanomaterials as low-cost and high-performance counter electrodes of dye-sensitized solar cells. Energy Environ. Sci. 6, 835-840 (2013).

18 Yun, S., Wang, L., Zhao, C., Wang, Y. \& Ma, T. A new type of low-cost counter electrode catalyst based on platinum nanoparticles loaded onto silicon carbide (Pt/SiC) for dye-sensitized solar cells. Phys. Chem. Chem. Phys. 15, 4286-4290 (2013).

19 Li, L. L., Chang, C.-W., Wu, H.-H., Shiu, J.-W., Wu, P.-T. \& Diau, E.W.-G. Morphological control of platinum nanostructures for highly efficient dye-sensitized solar cells. J. Mater. Chem. 22, 6267-6273 (2012).

20 Calogero, G., Calandra, P., Irrera, A., Sinopoli, A., Citro, I. \& Marco Di, G. A new type of transparent and low cost counter-electrode based on platinum nanoparticles for dye-sensitized solar cells. Energy Environ. Sci. 4, 1838-1844 (2011).

21 Wang, Y., Zhao, C., Qin, D., Wu, M., Liu, W. \& Ma, T. Transparent flexible Pt counter electrodes for high performance dye-sensitized solar cells. J. Mater. Chem. 22, 22155-22159 (2012)

22 Wei, T. C., Wan, C. C. Wang, Y. Y., Chen, C. M. \& Shiu, H. S. Immobilization of poly(N-vinyl-2-pyrrolidone)-capped platinum nanoclusters on indium-tin oxide glass and its application in dye-sensitized solar cells. J. Phys. Chem. C 111, 4847-4853 (2007).

23 Cho, S. J. \& Ouyang, J. Attachment of platinum nanoparticles to substrates by coating and polyol reduction of a platinum precursor. J. Phys. Chem. C 115, 8519-8526 (2011).

24 Sun, K., Fan, B. H. \& Ouyang, J. Y. Nanostructured platinum films deposited by polyol reduction of a platinum precursor and their application as counter electrode of dye-sensitized solar cells. J. Phys. Chem. C 114, 4237-4244 (2010).

25 Pavlovic, E., Quist, A. P., Gelius, U. \& Oscarsson, S. Surface functionalization of silicon oxide at room temperature and atmospheric pressure. J. Colloid Interface Sci. 254, 200-203 (2002).

26 Xia, Y. N., Xiong, Y. J., Lim, B. \& Skrabalak, S. E. Shape-controlled synthesis of meta nanocrystals: simple chemistry meets complex physics? Angew. Chem. Int. Ed. 48 60-103 (2009)

27 Chen, J., Herricks, T. \& Xia, Y. Polyol synthesis of platinum nanostructures: control of morphology through the manipulation of reduction kinetics. Angew. Chem. Int. Ed. 44, 2589-2592 (2005).

28 Ren, L. \& Xing, Y. Effect of pH on PtRu electrocatalysts prepared via a polyol process on carbon nanotubes. Electrochim. Acta 53, 5563-5568 (2008)

29 Wang, Y., Ren, J. W., Deng, K., Gui, L. L. \& Tang, Y. Q. Preparation of tractable platinum, rhodium, and ruthenium nanoclusters with small particle size in organic media. Chem. Mater. 12, 1622-1627 (2000).

30 Herricks, T., Chen, J. \& Xia, Y. Polyol synthesis of platinum nanoparticles: control of morphology with sodium nitrate. Nano Lett. 4, 2367-2371 (2004).

31 Shiu, J. W., Lan, Z. J., Chan, C. Y., Wu, H. P. \& Diau, E. W. G. Construction of a photoanode with varied TiO2 nanostructures for a Z907-sensitized solar cell with efficiency exceeding 10\%. J. Mater. Chem. A 2, 8749-8757 (2014).

32 Li, L. L., Chang, Y. C., Wu, H. P. \& Diau, E. W. G. Characterization of electron transport and charge recombination using temporally resolved and frequency-domain techniques for dye-sensitized solar cells. Int. Rev. Phys. Chem. 31, 420-467 (2012).

33 Chen, A. \& Holt-Hindle, P. Platinum-based nanostructured materials: synthesis, properties, and applications. Chem. Rev. 110, 3767-3804 (2010).

34 Debe, M. K. Electrocatalyst approaches and challenges for automotive fuel cells. Nature 486, 43-51 (2012).

$35 \mathrm{Wu}$, J. \& Yang, H. Platinum-based oxygen reduction electrocatalysts. Accounts Chem. Res. 46, 1848-1857 (2013).

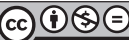

This work is licensed under a Creative Commons Attribution-NonCommercial-NoDerivs 3.0 Unported License. The images or other third party material in this article are included in the article's Creative Commons license, unless indicated otherwise in the credit line; if the material is not included under the Creative Commons license, users will need to obtain permission from the license holder to reproduce the material. To view a copy of this license, visit http://creativecommons.org/licenses/by-nc-nd/3.0/

Supplementary Information accompanies the paper on the NPG Asia Materials website (http://www.nature.com/am) 